\title{
Mushroom Poisoning Cases from an Emergency Department in Central Anatolia: Comparison and Evaluation of Wild and Cultivated Mushroom Poisoning
}

\author{
(1) Emin Fatih Vișneci¹, (1) Demet Acar¹, (1) Emine Nur Özdamar², (1) Mevlüt Güven¹, (1) Murat Patat¹ \\ ${ }^{1}$ Clinic of Emergency Medicine, Konya Training and Research Hospital, Konya, Turkey \\ ${ }^{2}$ Clinic of Medical Pharmacology, Konya Training and Research Hospital, Konya, Turkey
}

\begin{abstract}
Aim: To evaluate differences between cultivated and wild mushroom poisoning in terms of clinical characteristics, laboratory findings, and complications. We also aimed to determine the differences among patients in regard to presence of complications.

Materials and Methods: We evaluated adults who were diagnosed with mushroom poisoning at Konya Training and Research Hospital in a 4-year period between January 2014 and December 2017. The following characteristics of patients were recorded: Age, sex, complaints, time until hospital admittance, time until symptom onset, mushroom source, any interventions until patient arrived to the hospital, laboratory findings, complications like acute renal failure, neurotoxicity, rhabdomyolysis, cardiotoxicity and mortality, length of stay (LoS) at hospital, and patient discharge status. All analyses were performed on SPSS v21. Kolmogorov-Smirnov test was used to determine normality of distribution. Continuous variables were analyzed with the Mann-Whitney $U$ test and described as median (minimummaximum). Categorical variables were analyzed with chi-square test and described as frequency (percentage). The relationships between continuous variables were determined by calculating Spearman correlation coefficients.

Results: We included 168 patients (79 males and 89 females) in our study. The mean age was $46.66 \pm 18.66$ years. The cause of poisoning was cultivated mushrooms for 57 (33.9\%) patients and wild mushrooms for 111 (66.1\%) patients. It was found that patients in the wild mushroom group were older than the patients in the cultivated mushroom group $(p=0.006)$. Cultivated mushrooms were largely consumed by patients who live in metropolitan areas $(p<0.001)$. Patients who consumed wild mushrooms had higher troponin levels $(p=0.017)$, lower base excess values $(0.032)$ and longer LoS at hospital $(p=0.029)$. Although the sociodemographic studies of mushroom poisoning have been made numerously, this is the first study to draw attention to fact that it may also occur with cultured fungi.

Conclusion: Due to the climatic conditions in the area where our study has been conducted, frequent referrals to our institution occur with mushroom poisoning particularly in spring season. However, even in cultivated mushrooms, which are thought to be harmless, poisoning cases may also be observed that are usually seen with the wild fungi. Even in cases of cultured mushroom poisoning, symptoms may develop early and more serious complications may arise.
\end{abstract}

Keywords: Cultivated mushroom poisoning, wild mushroom poisoning, laboratory findings, clinical characteristics, complication

\section{Introduction}

Mushroom poisoning (MP) is an important cause of poisoning worldwide. Around 100 mushroom species are known to be poisonous to humans while 20 species contain lethal toxins $(1,2)$. Most deadly poisonings are caused by the amanita phalloides species, also known as the death cap; which is followed by the gyromitra (now grouped in the Discinaceae family) group (3). The severity of MP ranges from mild food-poisoning symptoms to serious life-threatening cases (4). Due to the number of unreported cases, the symptomatic similarity with other food poisonings, and the relatively low number of serious cases that 
require medical attention; determining the overall incidence of MP is difficult and usually requires a patient history indicating the consumption of mushrooms. As such, the incidence of MP is also unclear in Turkey (3). Another important point is that, although MP due to the foraging of mushrooms is much more frequent, commercially obtained mushrooms have been shown to cause poisonings in up to $5-7 \%$ of cases (5-7).

The clinical manifestation of MP may range from simple gastroenteritis to serious psychological effects, fatal liver and kidney failure (8). There are many factors that determine the severity of MP. Season, ingested amount, mushroom type, and preparation of the mushroom are some of these factors. As previously stated, patient history is very important in the diagnosis and care of MP. Identifying the type of mushroom is also important in some regions in which mushrooms that contain lethal toxins are endemic (9).

MP is categorized according to the time of symptom onset: Early onset ( $<6$ hours), late onset (6-24 hours) and delayed onset (>24 hours). Early onset poisoning usually presents with $\mathrm{Gl}$ and allergic symptoms and less commonly neurotoxic symptoms. Late onset poisoning presents with hepatotoxic and nephrotoxic symptoms and erythromelalgia syndrome. Delayed onset presents with hepatotoxic, nephrotoxic, delayed neurotoxic and rhabdomyolytic symptoms (10). The diagnosis and treatment of MP cases are based on patient history, clinical manifestation (including category), laboratory findings and identification of the responsible mushroom.

Early diagnosis and treatment are the most important factors that affect morbidity and mortality in MP. Although specific approaches in regard to mushroom type exist; treatment of MP is largely supportive even if the mushroom is identified. Treatment options include; activated charcoal, hemodialysis, hemoperfusion, hemofiltration, supplementation of fluidelectrolytes, symptomatic treatment, antiemetics, silibinin, $\mathrm{N}$-acetylcysteine, pyridoxine, benzodiazepines, aspirin, nicotinic acid, and high dose penicillin (6,10-18). The use of penicillin in most MP cases is currently being disputed (19); however, it is still a popular treatment option.

Our aim was to evaluate the clinical characteristics, laboratory findings and complications of wild and cultivated mushroom poisonings. In cultured mushroom poisoning, symptoms were developing earlier than wild fungi poisoning. We also observed that the incidence of serious complications such as acute renal failure and cardiotoxicity was higher in cultured mushroom poisoning. Acute renal failure developed in 22 and (37.2\%), cardiotoxicity in 3 of 59 patients (5.08\%) who were poisoned by cultured mushroom.

\section{Materials and Methods}

The study was a retrospective evaluation of patients, admitted to Konya Training and Research Hospital between 01 January 2014 and 31 December-2017 who were diagnosed with MP. Patient inclusion criteria were: (1) Being older than 18 years of age, (2) accepting treatment from our clinic, (3) remaining at our clinic until their results were obtained or the end of treatment. Twenty-one patients were excluded from the study; 8 due to being younger than 18, 7 due to refusal of treatment, and 6 due to leaving the hospital while primary care/treatment was continuing (these 6 patients did not inform that they were leaving and did not fill an AMA form; thus they were not included in the study. Whereas patients who had sufficient data and later had filled an AMA form were included in the final evaluation). A final total of 168 patients were included in the study.

Local ethics committee approval was obtained at 28 March 2017/985 from University of Necmettin Erbakan and the Helsinki declaration and good clinical practice guidelines were followed for the entirety of the study.

The following characteristics of patients were recorded: Age, sex, complaints, time until hospital admittance, time until symptom onset, mushroom source, any interventions until patient arrived to the hospital, laboratory findings, complications, length of stay (LOS) at hospital, and patient discharge status. The following conditions were accepted as complications: Acute renal failure, neurotoxicity, cardiotoxicity, rhabdomyolysis. The patients were asked about the features of mushroom. Data from the patients who have information about the mushroom species were recorded. If the patient didn't have information about the mushroom species, they were asked about the shape and the source of mushrooms. The mushrooms with a pale cap and stalk are accepted as cultivated mushroom.

\section{Statistical Analysis}

All analyses were performed on SPSS v21. KolmogorovSmirnov test was used to determine normality of distribution. Continuous variables were analyzed with the Mann-Whitney $U$ test and described as median (minimum-maximum). Categorical variables were analyzed with chi-square test and described as frequency (percentage). The relationships between continuous variables were determined by calculating Spearman correlation coefficients.

\section{Results}

We included 168 patients (79 males and 89 females) in our study. The mean age was $46.66 \pm 18.66$ years. The cause of poisoning was cultivated mushrooms for 57 (33.9\%) patients and wild 
Table 1. Patients' Demographics and characteristics regarding source of consumed mushroom

\begin{tabular}{|c|c|c|c|}
\hline & Wild mushroom $(n=111)$ & Cultivated mushroom $(n=57)$ & $\mathbf{p}$ \\
\hline Age & $47(17-88)$ & $33(18-79)$ & $0.006^{*}$ \\
\hline \multicolumn{4}{|l|}{ Gender } \\
\hline Female & $60(54.1 \%)$ & $29(50.9 \%)$ & \multirow{2}{*}{-0.820} \\
\hline Male & $51(45.9 \%)$ & $28(49.1 \%)$ & \\
\hline \multicolumn{4}{|l|}{ Location } \\
\hline Rural & $37(33.3 \%)$ & $4(7.0 \%)$ & \multirow{2}{*}{$-<0.001^{* *}$} \\
\hline Urban & $74(67.7 \%)$ & $53(93.0 \%)$ & \\
\hline \multicolumn{4}{|l|}{ Educational status } \\
\hline Primary school and below & $53(47.7 \%)$ & $18(31.6 \%)$ & \multirow{3}{*}{0.132} \\
\hline Secondary school & $11(9.9 \%)$ & $7(12.3 \%)$ & \\
\hline High school and above & $47(42.3 \%)$ & $32(56.1 \%)$ & \\
\hline Complications & $55(49.5 \%)$ & $29(50.9 \%)$ & 1.000 \\
\hline \multicolumn{4}{|l|}{ Discharge } \\
\hline After full recovery & $102(91.9 \%)$ & $52(91.2 \%)$ & \multirow{2}{*}{-1.000} \\
\hline Patient request (AMA) & $9(8.1 \%)$ & $5(8.8 \%)$ & \\
\hline Time of symptom onset (hours) & $4(0-96)$ & $4(0-24)$ & 0.675 \\
\hline Systolic blood pressure & $120(100-170)$ & $120(100-145)$ & 0.370 \\
\hline Diastolic blood pressure & $70(45-100)$ & $70(64-90)$ & 0.699 \\
\hline Pulse (BPM) & $78(65-115)$ & $79(65-92)$ & 0.168 \\
\hline Urea & $29(12-63)$ & $27(10-59)$ & 0.083 \\
\hline Creatinine & $0.77(0.50-1.24)$ & $0.80(0.44-1.48)$ & 0.283 \\
\hline AST & $22(7-718)$ & $23(12-88)$ & 0.377 \\
\hline ALT & $17(9-860)$ & $19(7-79)$ & 0.303 \\
\hline Direct bilirubin & $0.10(0.01-0.40)$ & $0.10(0.03-0.40)$ & 0.401 \\
\hline Indirect bilirubin & $0.4(0.1-1.6)$ & $0.4(0.1-2.9)$ & 0.458 \\
\hline INR & $0.9(0.8-1.9)$ & $1(0.8-1.5)$ & 0.071 \\
\hline Troponin & $0.04(0-0.73)$ & $0.04(0-0.09)$ & $0.017^{*}$ \\
\hline CK & $93(12-2166)$ & $89.5(1-725)$ & 0.734 \\
\hline CK-MB & $1.8(0-91)$ & $1(0-54)$ & 0.066 \\
\hline $\mathrm{pH}$ & $7.39(7.28-7.52)$ & $7.39(7.32-7.47)$ & 0.792 \\
\hline $\mathrm{HCO}_{3}$ & $23.05(16.0-32.0)$ & $23.8(14.3-28.3)$ & 0.098 \\
\hline Lactate & $1.2(0.13-12.70)$ & $1.5(0.6-10.7)$ & 0.201 \\
\hline Base excess & $-0.7(-10-6.6)$ & $-0.05(-12.2-3)$ & $0.032^{*}$ \\
\hline LoS at hospital (days) & $2(0-13)$ & $1(0-6)$ & $0.029 *$ \\
\hline \multirow{2}{*}{\multicolumn{4}{|c|}{ Data given as median (minimum - maximum) or frequency (percentage) }} \\
\hline & & & \\
\hline
\end{tabular}

mushrooms for 111 cases (66.1\%). It was found that patients in the wild mushroom group were older than the patients in the cultivated mushroom group ( $p=0.006)$. Cultivated mushrooms were largely consumed by patients who live in metropolitan areas $(p<0.001)$. Patients who consumed wild mushrooms had higher troponin levels ( $p=0.017$ ), lower base excess values (0.032) and longer LoS at hospital $(p=0.029)$ (Table 1). Fifty-five (49.5\%) patients in the wild mushroom group, and 29 (50.9\%) patients in the cultivated mushroom group developed complications. Complications were more frequent in patients who lived in urban and metropolitan areas than those who lived in rural areas $(p<0.001)$, and in patients with higher educational status $(p=0.002)$. Symptoms were seen earlier in patients who had complications than those who had not $(p=0.001)$. Patients with 
Table 2. Patients' demographics and characteristics regarding complications

\begin{tabular}{|c|c|c|c|}
\hline \multicolumn{4}{|c|}{ Complications } \\
\hline & Absent $(n=84)$ & Present $(n=84)$ & $\mathrm{p}$ \\
\hline Age & $41.5(17-88)$ & $38.5(18-81)$ & 0.105 \\
\hline \multicolumn{4}{|l|}{ Gender } \\
\hline Female & $41(48.8 \%)$ & $48(57.1 \%)$ & \multirow{2}{*}{0.354} \\
\hline Male & $43(51.2 \%)$ & $36(42.9 \%)$ & \\
\hline \multicolumn{4}{|l|}{ Location } \\
\hline Rural & $34(40.5 \%)$ & $7(8.3 \%)$ & \multirow{2}{*}{$<0.001^{* *}$} \\
\hline Urban & $50(59.5 \%)$ & $77(91.7 \%)$ & \\
\hline \multicolumn{4}{|l|}{ Educational status } \\
\hline Primary school and below & $44(52.4 \%)$ & $27(32.1 \%)$ & \multirow{3}{*}{$0.002^{*}$} \\
\hline Secondary school & $3(3.6 \%)$ & $15(17.9 \%)$ & \\
\hline High school and above & $37(44.0 \%)$ & $42(50.0 \%)$ & \\
\hline \multicolumn{4}{|l|}{ Discharge } \\
\hline After full recovery & $79(94.0 \%)$ & $75(89.3 \%)$ & \multirow{2}{*}{-0.402} \\
\hline Patient request (AMA) & $5(6.0 \%)$ & $9(10.7 \%)$ & \\
\hline Time of symptom onset (hours) & $4.5(0.5-72)$ & $3(0-96)$ & $0.001 * *$ \\
\hline Systolic blood pressure & $116.5(105-170)$ & $120(100-170)$ & 0.702 \\
\hline Diastolic blood pressure & $70(45-100)$ & $70(60-100)$ & 0.181 \\
\hline Pulse (BPM) & $75(65-95)$ & $79.5(65-115)$ & 0.008 \\
\hline Urea & $29.5(10-63)$ & $28(10-62)$ & $0.044^{*}$ \\
\hline Creatinine & $0.8(0.50-1.48)$ & $0.79(0.44-1.48)$ & 0.762 \\
\hline AST & $22(7-76)$ & $23.5(7-718)$ & 0.083 \\
\hline ALT & $16.5(7-92)$ & $18.5(9-860)$ & $0.020^{*}$ \\
\hline Direct bilirubin & $0.10(0.01-0.40)$ & $0.10(0.03-0.40)$ & $0.025^{*}$ \\
\hline Indirect bilirubin & $0.4(0.1-2.9)$ & $0.4(0.1-1.4)$ & 0.914 \\
\hline INR & $1(0.8-1.5)$ & $1(0.8-1.9)$ & 0.916 \\
\hline Troponin & $0.04(0-0.4)$ & $0.04(0-0.73)$ & 0.816 \\
\hline CK & $97(1-725)$ & $87.5(33-2166)$ & 0.744 \\
\hline CK-MB & $10(0-91)$ & $1(0-27)$ & $<0.001^{* * *}$ \\
\hline $\mathrm{pH}$ & $7.38(7.28-7.52)$ & 7.39 (7.3-7.48) & 0.443 \\
\hline $\mathrm{HCO}_{3}$ & $23.7(14.3-29.4)$ & $23(17-32)$ & 0.106 \\
\hline Lactate & $1.4(0.13-12.7)$ & $1.2(0.6-12)$ & 0.267 \\
\hline Base excess & $-0.5(-12.2-3.6)$ & $-0.3(-9-6.6)$ & 0.826 \\
\hline LoS at hospital (days) & $2(0-4)$ & $0(0-13)$ & $<0.001^{* *}$ \\
\hline \multicolumn{4}{|c|}{ Data given as median (minimum - maximum) or frequency (percentage) } \\
\hline LoS: Length of stay, INR: International & nine transaminase, $\mathrm{A}$ & ansferase & \\
\hline
\end{tabular}

complications had lower urea $(p=0.044)$ and CK-MB $(p<0.001)$ values while they had higher ALT $(p=0.020)$ and direct bilirubin $(p=0.025)$ values. Hospitalization time (LoS) were longer for patients without complications $(\boldsymbol{p}<0.001)$ (Table 2$)$. There was a positive moderate correlation between the time interval until symptom onset and hospitalization (LoS) time ( $r=0.416$; $\mathrm{p}<0.001)$ and also a positive weak correlation between age and hospitalization (LoS) time $(r=0.239 ; p=0.003)$.

\section{Discussion}

Although determining the incidence of MP through retrospective studies has various limitations, we believe that overall MP 
incidence is lower in our area than other parts of our country. There was no death due to MP in our study. We found that cultivated mushrooms were mostly consumed by patients in the metropolitan area. Patients who consumed wild mushrooms had higher troponin levels, lower base excess values, and longer LoS at hospital. Furthermore, patients who had complications had higher ALT and bilirubin levels while they were surprisingly found to have lower urea and CK-MB values, earlier symptom onset, and shorter LoS at hospital. We also identified various results of which some could be compared with available literature and some that could not.

Due to the regional differences of fungi population and poisonousness, we aimed to assess domestic reports to evaluate MP incidence in Turkey and found that, in 2008 a total of 1210 MP cases were reported to the national poisoning center, which represented $43.54 \%$ of all poisonings from food sources (20). However, epidemiologic and clinical studies of MP in Turkey are limited to single-center studies which only represent local poisoning cases. Five major single-center Turkish studies cumulatively including a total of 1411 patients reported a total of 26 deaths (1.8\%) due to MP $(3,6,7,21,22)$ which is comparable to various studies (18) but lower than studies which include patients poisoned with amanita phalloides $(23,24)$. Reports from other countries and regions such as the United States and Europe estimate that there are around 100-200 yearly fatalities due to MP $(25,26)$. A study by Yamaura (27), reported a total of 1920 cases and 10 deaths between 2001-2010 in Japan. In our study we did not observe any death due to MP, which may be explained by the relatively low rate of wild MP cases, fast arrival at hospital, prompt treatment, and low rate of serious complications.

Various domestic studies $(6,7)$ and a report from the Food and Agriculture Organization (FAO) of the United Nations (5) show that cultivated mushrooms represent $5-7 \%$ of MP cases; which is an important finding when cultivated mushrooms are accepted as 'safe' by the general population. We report a very high rate ( $n=57,33.9 \%)$ of cultivated MP in our study. This rate may be explained by the unfavorable climate for mushrooms and the unpopularity of mushroom foraging in our region, which may have increased the proportion of cultivated MP cases. Some studies from Turkey report rates of MP due to foraging close to $100 \%$, while others report poisonings from commercial mushrooms in up to $12 \%$ of their cases (21). Analysis of cases based on the source of mushrooms (wild or cultivated) showed that cultivated mushrooms were the main source of poisoning in patients from the metropolitan area. We also found that troponin levels, base excess and LoS at hospital were lower in the cultivated mushroom group. To our knowledge, our rate is the highest reported rate of MP due to cultivated mushrooms in Turkey. This limits the feasibility of comparing findings with other studies in this matter.

The clinical course of MP is usually based on the type of mushroom, which is directly related to the onset time of symptoms. Early onset shows better prognosis while patients with late and delayed onset show poor prognosis $(6,7,28,29)$. In our study, when patients were grouped in regard to development of complications, we found that complications were more frequent in patients who lived in urban and metropolitan areas compared to rural areas. Patients with complications had higher ALT and direct bilirubin levels as expected. However, we also found that patients with complications had earlier onset, shorter LoS at hospital, lower urea and CK-MB values in comparison to patients without complications. This is a surprising finding which is contrary to the literature $(1,3,9,21)$ may simply be explained by incorrect patient history. However, another explanation may lie in our definition of complication; which included mild conditions, thus our statistics may have been affected. In the light of these findings, we believe that complications are not rare in cultivated MP and also, it may be plausible to suggest that mild complications do not affect prognosis in MP. Our findings and our conclusion requires further studies and explanations which may be obtained by analysis of complications separately.

There are several strengths of our study. Firstly, we have a large group of patients due to our center being a major hospital in area; secondly, our study evaluated patients based on the source of mushroom and the presence of complications, rather than the more common "demographic-descriptive" assessment. Finally, our study showed that the laboratory findings of these clinically indistinguishable conditions were also similar. There are also limitations to our study. Firstly, we did not identify mushroom species; however, although identification of mushroom is helpful in treatment, it is not an absolute requirement for the effective management of MP (8). We did not evaluate the effect of season on MP which has been shown to be an important factor in various studies (6,30); however, we were interested in identifying the differences in terms of mushroom source and complications; thus evaluating seasonal effects were not necessary. Secondly, we did not separate mild and severe complications which may explain our results that were in contrast with the literature. Finally, the retrospective nature of the study is also a limitation.

\section{Conclusion}

In conclusion, we suggest that educational measures should be taken to instruct the general public -not only about the risks of mushroom foraging- but also about precautions that should be taken in the preparation and consumption of cultivated mushrooms. We also want to remind clinicians that the most 
important step in the approach to MP is identifying mushroom ingestion from the patient history and promptly beginning supportive treatment even if the source is cultivated mushrooms. We believe our findings provide a new approach to complications in MP and shed light on the differences (and similarities) between cultivated and wild MP. Some of our findings are in contrast with the literature; however, we believe this is largely due to the perception and definition of mild and severe complications. These results may be explained by future studies that separate complications by severity.

\section{Ethics}

Ethics Committee Approval: Local ethics committee approval was obtained at 28 March 2017/985 from University of Necmettin Erbakan and the Helsinki declaration and good clinical practice guidelines were followed for the entirety of the study.

Informed Consent: It was taken.

Peer-review: Internally peer-reviewed.

\section{Authorship Contributions}

Surgical and Medical Practices: D.A., E.F.V., Concept: D.A., E.F.V., Design: D.A., Data Collection or Processing: M.P., Analysis or Interpretation: D.A., E.F.V., Literature Search: E.N.Ö., M.G., Writing: D.A., E.F.V.

Conflict of Interest: No conflict of interest was declared by the authors.

Financial Disclosure: The authors declared that this study received no financial support.

\section{References}

1. Erguven M, Yilmaz O, Deveci M, Aksu N, Dursun F, Pelit M, et al. Mushroom poisoning. Indian J Pediatr. 2007;74:847-52.

2. Berger KJ, Guss DA. Mycotoxins revisited: part I. J Emerg Med. 2005;28:53-62.

3. Colak S, Kandis H, Afacan MA, Erdogan MO, Gunes H, Kaya E, et al. Assessment of patients who presented to the emergency department with mushroom poisoning. Hum Exp Toxicol. 2015;34:725-31.

4. Unverir P, Soner BC, Dedeoglu E, Karcioglu O, Boztok K, Tuncok Y. Renal and hepatic injury with elevated cardiac enzymes in Amanita phalloides poisoning: a case report. Hum Exp Toxicol. 2007;26:757-61.

5. GECAN JS, Cichowicz SM. Toxic Mushroom Contamination of Wild Mushrooms in Commercial Distribution. J Food Prot. 1993;56:730-4.

6. Eren SH, Demirel Y, Ugurlu S, Korkmaz I, Aktas C, Güven FM. Mushroom poisoning: retrospective analysis of 294 cases. Clinics (Sao Paulo). 2010;65:491-6.

7. Unluoglu I, Tayfur M. Mushroom poisoning: an analysis of the data between 1996 and 2000. Eur J Emerg Med. 2003;10:23-6.

8. Pajoumand A, Shadnia S, Efricheh H, Mandegary A, Hassanian-Moghadam H, Abdollahi M. A retrospective study of mushroom poisoning in Iran. Hum Exp Toxicol. 2005;24:609-13.

9. Brayer AF, Schneider S, Cevik A. Mushroom poisoning. Emergency medicine: A comprehensive study guide. McGraw-Hill. 2004.
10. Diaz JH. Syndromic diagnosis and management of confirmed mushroom poisonings. Crit Care Med. 2005;33:427-36.

11. Bedry R, Baudrimont I, Deffieux G, Creppy EE, Pomies JP, Ragnaud JM, et al. Wild-mushroom intoxication as a cause of rhabdomyolysis. N Engl J Med. 2001;345:798-802.

12. Nakajima N, Ueda M, Higashi N, Katayama Y. Erythromelalgia associated with Clitocybe acromelalga intoxication. Clin Toxicol (Phila). 2013;51:451-4.

13. Michelot D, Toth B. Poisoning by Gyromitra esculenta--a review. J Appl Toxicol. 1991;11:235-43.

14. Diaz JH. Evolving global epidemiology, syndromic classification, general management, and prevention of unknown mushroom poisonings. Crit Care Med. 2005;33:419-26.

15. Beuhler MC, Sasser HC, Watson WA. The outcome of North American pediatric unintentional mushroom ingestions with various decontamination treatments: an analysis of 14 years of TESS data. Toxicon. 2009;53:437-43.

16. Ergin N. Mantar zehirlenmeleri ve tedavide genel yaklașım. Türk Hij Den Biyol Derg. 2000;57:109-18.

17. Santi L, Maggioli C, Mastroroberto M, Tufoni M, Napoli L, Caraceni P. Acute Liver Failure Caused by Amanita phalloides Poisoning. Int J Hepatol. 2012;2012:487480.

18. Altıntop L. OMÜ Tıp Fakültesi Acil Servise Başvuran mantar Intoksikasyonlarının Bir Yıllık Değerlendirilmesi. Akademik Acil Tıp Derg. 2004;2:23-7.

19. Karlson-Stiber C, Persson H. Cytotoxic fungi-an overview. Toxicon. 2003;42:339-49.

20. Özcan N, İkincioğulları D. Ulusal Zehir Danışma Merkezi 2008 Yılı Çalışma Raporu Özeti. Turk Hij Den Biyol Derg. 2009;66:29-58.

21. Cevik AA, Unluoglu I. Factors Affecting Mortality and Complications in Mushroom Poisonings Over a 20 Year Period: A Report from Central Anatolia. Turk J Emerg Med. 2016;14:104-10.

22. Yardan T, Baydin A, Eden AO, Akdemir HU, Aygun D, Acar E, et al. Wild mushroom poisonings in the Middle Black Sea region in Turkey: analyses of 6 years. Hum Exp Toxicol. 2010;29:767-71.

23. Enjalbert F, Rapior S, Nouguier-Soulé J, Guillon S, Amouroux N, Cabot C. Treatment of amatoxin poisoning: 20-year retrospective analysis. J Toxicol Clin Toxicol. 2002;40:715-57.

24. Jander S, Bischoff J. Treatment of Amanita phalloides poisoning: I. Retrospective evaluation of plasmapheresis in 21 patients. Ther Apher. 2000;4:303-7.

25. Ellenhorn MJ, Seth S, Ordog G, Wasserberger J. Ellenhorn's medical toxicology: diagnosis and treatment of human poisoning. 1997: Williams \& Wilkins.

26. Mengs U, Pohl RT, Mitchell T. Legalon ${ }^{\circledR}$ SIL: the antidote of choice in patients with acute hepatotoxicity from amatoxin poisoning. Curr Pharm Biotechnol. 2012;13:1964-70.

27. Yamaura Y. Recent trends of mushroom poisoning in Japan. Chudoku Kenkyu. 2013;26:39-43.

28. Schenk-Jaeger KM, Rauber-Lüthy C, Bodmer M, Kupferschmidt H, KullakUblick GA, Ceschi A. Mushroom poisoning: a study on circumstances of exposure and patterns of toxicity. Eur J Intern Med. 2012;23:85-91.

29. Yelken, B., Erkan A. Mantar zehirlenmeleri: 104 olgunun değerlendirmesi. Journal of the Turkish Society of Intensive Care, 2009.7:12-6.

30. Nordt SP, Manoguerra A, Clark RF. 5-Year analysis of mushroom exposures in California. West J Med. 2000;173:314-7. 